\title{
A Corte Internacional de Justiça e o Brasil: uma necessária reconciliação
}

Fecha de recepción: 16 de febrero de 2015

Fecha de aceptación: 14 de septiembre de 2015

Doi: dx.doi.org/10.12804/acdi9.1.2016.02

\section{Juliette Robichez}

\section{André Lamartin Montes**}

Resumo: $\mathrm{O}$ artigo em questão aborda de maneira historicista as relações entre a Corte Internacional de Justiça e o Estado brasileiro, no intento de rediscutir o papel deste e reformular conceitos tradicionais. O objetivo deste trabalho é de reconciliar o Brasil com a principal jurisdição internacional. Com o propósito de analisar de maneira crítica as razões que justificam a não adesão pelo Brasil à cláusula facultativa de jurisdição obrigatória, prevista no artigo 36-2 do Estatuto da CIJ, realizou-se uma pesquisa qualitativa, bibliográfica e documental baseada em procedimentos metodológicos comparativos e históricos, guiada por uma abordagem dedutiva amparada em estudo de casos. O artigo utilizou textos de internacionalistas brasileiros renomados, porém, para suprir a escassez de literatura nacional sobre o tema, se refere também amplamente à doutrina estrangeira, muito mais prolixa.

* Mestre em Direito Internacional Privado e Direito do Comércio Internacional e doutora em Direito pela Universidade Paris I - Panthéon Sorbonne (França); professora de Direito Internacional na Universidade Católica de Salvador (UCSAL) (Brasil).

** Graduado em Direito pela Faculdade Ruy Barbosa (Brasil); premiado pelo Programa Estudos Latino-Americanos Paul E. Sigmund (University of Princeton); advogado internacional.

Para citar este artículo: Robichez, Juliette \& Montes, André L., "A Corte Internacional de Justiça e o Brasil: uma necessária reconciliação", Anuario Colombiano de Derecho Internacional (ACDI), 2016, 9, pp. 51-80. Doi: dx.doi.org/10.12804/acdi9.1.2016.02 
Palavras-chave: Corte Internacional de Justiça, artigo 36-2, cláusula facultativa de jurisdição obrigatória, Brasil, adesão.

La Corte Internacional de Justicia y Brasil: una reconciliación necesaria

Resumen: En 1948, Brasil se colocó al margen del más importante tribunal internacional del momento al no adherirse a la cláusula de jurisdicción obligatoria prevista en el artículo 36-2 del Estatuto de la Corte Internacional de Justicia (CIJ). El objetivo central de este trabajo es convencer al Estado brasileño de reconciliarse con la Corte e integrar al Secretariado General de la ONU una declaración de adhesión a la cláusula de jurisdicción obligatoria de la CIJ. Por lo tanto, el artículo analiza la evolución histórica de la CIJ, estudia su papel en el sistema internacional y evalúa las razones que han llevado a Brasil a rechazar la competencia contenciosa de la Corte. Dicho de otra forma, se analizan los ejemplos de países como Francia y los Estados Unidos, quienes también habían decidido rechazar la cláusula de jurisdicción obligatoria; se evalúan los argumentos contrarios a la posición de la Corte y se demuestra cómo eso contribuyó a la paz mundial a través de un fortalecimiento del derecho internacional público.

Palabras clave: Corte Internacional de Justicia, artículo 36-2, cláusula facultativa de jurisdicción obligatoria, Brasil, adhesión.

\section{The International Court of Justice and Brazil: a Necessary Reconciliation}

Abstract: In 1948, Brazil placed itself at the margin of the most important international tribunal of the moment by not adhering to the mandatory jurisdiction clause set out in Article 36-2 of the Statute of the International Court of Justice (I.C.J.). The central objective of this work is to convince the Brazilian State to file with the Secretary General of the United Nations (UN) a declaration of adherence to the mandatory jurisdiction clause of the I.C.J. Accordingly, the article analyzes the historical evolution of the ICJ, studies its role in the international system and evaluates the reasons that led Brazil to reject the contentious jurisdiction of the Court. Put another way, it analyzes the examples of countries such as France and the United 
States, which have also decided to reject the mandatory clause; it evaluates the arguments contrary to the position of the Court and demonstrates how it has contributed to world peace through the strengthening of international public law.

Keywords: International Court of Justice, Article 36-2, optional clause to mandatory jurisdiction, Brazil, adhesion.

\section{Introdução}

Em 1795, o filósofo prussiano Immanuel Kant ${ }^{1}$ ousou sonhar com um mundo onde os Estados procurassem resolver seus problemas através do diálogo, da razão e da aplicação de princípios morais, relegando ao esquecimento o uso da força. Para tanto, vislumbrou o desenvolvimento de um direito internacional cosmopolita que galgasse aceitação universal e proporcionasse à comunidade internacional um meio pacífico para solucionar suas controvérsias.

Portanto, não é de se surpreender que quando a Organização das Nações Unidas (ONU) foi criada em 1945, Kant foi tido por muitos como sendo seu patrono intelectual. Como o próprio preâmbulo da Carta de São Francisco estipula, a ONU fora concebida para preservar as gerações vindouras do flagelo da guerra, que por duas gerações havia assolado seus criadores e ceifado incontáveis milhões de vidas. ${ }^{2}$ Criou-se uma organização internacional com uma missão realmente ambiciosa: tornar ilegal o uso da força pelos Estados como meio de solução de suas controvérsias. $\mathrm{O}$ dinamismo da sociedade internacional contemporânea concretizou-se notadamente pelo estímulo do uso de instrumentos alternativos de resolução das lides internacionais, visando o primado do Direito. O fenômeno de jurisdicionalização do direito internacional, quer dizer da proliferação de instâncias judiciais a partir da Segunda Guerra Mundial, leciona Wagner Menezes, representa "um avanço nas relações internacionais no seu marco histórico civilizatório". 3

\footnotetext{
1 Kant, Immanuel, To perpetual peace, Hacket, Indianapolis, 2003, p. 18.

2 Lissitzyn, O. J., The International Court of Justice - Its role in the maintenance of international peace and security, The Lawbook Exchange, New Jersey, 2008, p. 2.

3 Menezes, Wagner, Tribunais internacionais. Jurisdição e competência, Saraiva, São Paulo, 2013, p. 25.
} 
Foi justamente para garantir a consecução desse objetivo, em 1946, que se concebeu a Corte Internacional de Justiça (CIJ), o órgão jurisdicional supremo da ONU e o mais importante foro de solução internacional da atualidade, imbuída de uma competência internacional ampla. Além de prestar esclarecimentos sobre questões de direito internacional, ela pode também dirimir quaisquer contenciosos entre Estados membros da ONU.

Contudo, para que a CIJ possa solucionar um conflito entre Estados não basta apenas que eles sejam membros da ONU. É imprescindível que reconheçam previamente a competência contenciosa da Corte, o que pode ser feito aderindo-se à cláusula de jurisdição obrigatória prevista no artigo $36 \$ 2$ do seu Estatuto. Apesar de ser um de seus membros originários e um dois países que mais juízes elegeu para à Corte, o Brasil decidiu colocar-se à margem do mais importante órgão judicial internacional. Desde 1948, o país vem se recusando a aceitar a competência contenciosa da Corte, negando-se reiteradamente a aderir à cláusula de jurisdição obrigatória. ${ }^{4}$

Tal atitude denota uma descrença no direito internacional pouco característica da carta magna brasileira de 1988. No seu artigo $4^{\circ}$, a Constituição lista entre os princípios que devem reger o Brasil nas suas relações internacionais: a solução pacífica dos conflitos, a defesa da paz e a cooperação dos povos para o progresso da humanidade. Portanto, percebe-se que o diploma de 1988 é bastante receptivo ao direito internacional, fazendo com que a posição refratária adotada pelo Brasil perante a CIJ seja incongruente com o texto constitucional.

Destarte, a hipótese de pesquisa aventada neste artigo é a de que o Brasil errou ao se excluir do mais importante órgão judicial internacional, devendo aderir imediatamente à cláusula de jurisdição obrigatória. A relevância social da pesquisa repousa na necessidade de persuadir o Estado brasileiro a se reintegrar ao âmago da mais importante corte do sistema internacional e reingressar no rol de países que aceitam a jurisdição obrigatória da CIJ, saindo assim da lista dos que agem como "verdadeiros Estados fora da lei". ${ }^{5}$

Teoricamente, justifica-se a pesquisa devido à necessidade de se tomar posição a favor de uma corrente de pensadores que acreditam na

\footnotetext{
4 United Nations, The International Court of Justice - Questions and answers about the principal judicial organ of the United Nations, 10 ed., United Nations, New York, 2000, p. 2.

5 Menezes, Tribunais internacionais..., op. cit., p. 246.
} 
manutenção da paz internacional através do diálogo, da razão, da aplicação de princípios morais e da justiça institucionalizada. Além disso, deve-se preencher uma lacuna, já que os manuais brasileiros de direito internacional público não explicam, ou o fazem de maneira muito sucinta, a posição de desdém do país no tocante ao principal foro internacional. Por todas essas razões, realizou-se uma pesquisa qualitativa, bibliográfica e documental baseada em procedimentos metodológicos comparativos e históricos, guiada por uma abordagem dedutiva amparada no estudo de casos.

Com o intento de re-discutir o papel do Estado brasileiro no que tange à jurisdição internacional, a pesquisa foi dividida em cinco capítulos. No primeiro capítulo, analisou-se brevemente a gênese e evolução histórica da CIJ para que se tenha uma dimensão clara do seu papel no sistema internacional. No segundo capítulo, apresentou-se a atual posição do Brasil com o intuito de se desvendar o porquê de o país não querer aderir à cláusula de jurisdição obrigatória. No terceiro capítulo, tentou-se contextualizar a posição brasileira, estudando os precedentes de países como a França e os EUA que também abandonaram a cláusula de jurisdição obrigatória. No quarto capítulo, deu-se voz aos detratores da Corte com o propósito de se rebater os argumentos contrários a sua atuação. No quinto capítulo, estudou-se o papel das decisões e pareceres da CIJ para demonstrar como a Corte também contribui para a manutenção da paz mundial através do fortalecimento do direito internacional público.

\section{CIJ - Gênese e evolução histórica}

A gênese da CIJ pode ser traçada a partir da primeira conferência internacional de paz convocada pelo czar Nicolau II e realizada em Haia em 1899. Nesta ocasião, 26 Estados assinaram um tratado sobre a resolução pacífica de controvérsias que resultou na criação da Corte Permanente de Arbitragem em 1902. Já durante a segunda conferência de paz realizada em 1907, os Estados tentaram ir além da arbitragem e cogitaram a criação de um tribunal internacional dedicado exclusivamente à resolução pacífica de controvérsia pela via judicial. ${ }^{6}$ Apesar da ideia ter suscitado grande

\footnotetext{
6 Para maiores aprofundamentos, Menezes, ibíd., p. 29 e s. Quoc Dinh, Nguyen; Daillier, Patrick; Forteau, Mathias; Pellet, Alain, Droit international public, $8^{\circ}$ ed., LGDJ, Paris, 2010, p. 985 e s.
} 
interesse, não se chegou a um consenso a respeito do mecanismo de seleção de juízes e o projeto foi temporariamente relegado ao plano teórico. ${ }^{7}$

Foi preciso o morticínio generalizado da Primeira Guerra Mundial para que a ideia de se criar um tribunal internacional para a resolução de conflitos entre Estados fosse finalmente implementada. Durante a conferência de Paris, o Presidente norte-americano W. Wilson propôs a criação da Liga das Nações, uma organização internacional que viabilizasse a resolução pacífica de controvérsias entre Estados através do diálogo e da negociação diplomática aberta. Quando seus membros não conseguissem resolver um dissídio pela via diplomática, os artigos 12 e 13 do ato constitutivo da Liga impunham que os Estados recorressem à via arbitral ou judicial. ${ }^{8}$ Para viabilizar essa segunda opção, criou-se a Corte Permanente de Justiça Internacional (CPJI) em 1921.' Situada em Haia, foi o primeiro tribunal internacional do gênero. Apesar de ser financiada pela Liga das Nações, a corte permanente não era o seu órgão judicial e seu estatuto não fazia parte do tratado constitutivo da Liga. Portanto, era possível ser membro da organização internacional sem necessariamente ser membro da CPJI.

Tragicamente, a CPJI sucumbiu perante a Segunda Guerra mundial, e somente durante a conferência de São Francisco retomou-se mais uma vez a ideia de se criar um tribunal internacional. Isso foi feito em 1946 quando a Corte Internacional de Justiça foi concebida para ser o mais importante órgão judicial da ONU. A CIJ é composta por 15 juízes de diferentes países e fica situada no Palácio da Paz em Haia, o mesmo local onde a CPJI costumava funcionar. ${ }^{10}$ Todavia, o espólio da antecessora se limita a isso: "Os poderes, a ação e o contexto de justiça da ONU são outros muito mais amplos e concretos do que aqueles em que funcionava". ${ }^{11}$ A Corte é

\footnotetext{
Pomerance, Michla, The United States and the World Court as the Supreme Court of the nations: dreams, illusions and disillusion, Martinus Nijhoff Publishers, Dordrecht, 1997, p. 55.

8 Amr, Mohamed S., The role of the International Court of Justice as the principal judicial organ of the United Nations, Kluwer Law International, Haia, 2003, p. 12.

9 Araripe, Luiz de A., "Tratado de Versalhes", in Magnoli, Demétrio (Org.), História da paæ, Contexto, São Paulo, 2008, p. 226.

10 Singh, Nagendra, The role and record of the International Court of Justice, Martinus Nijhoff Publishers, Dordrecht, 1989, p. 1.

11 Menezes, Tribunais internacionais..., op. cit., p. 138. Contra Quoc Dinh, Daillier, Forteau \& Pellet, Droit international public, op. cit., p. 987 e s.
} 
acessível apenas aos Estados e à ONU, não dirimindo controvérsias entre indivíduos. A CIJ é a única verdadeira jurisdição internacional universal que goza de competência geral. Aliás, segundo o artigo 92 da Carta da ONU, ela é o "principal órgão judiciário das Nações Unidas". Seu estatuto foi anexado à Carta de São Francisco e faz parte integrante do tratado constitutivo da ONU, ${ }^{12}$ o que significa dizer que todos os 193 Estados membros da ONU são também membros da CIJ. ${ }^{13}$

Todavia, para que possam figurar no polo passivo de um processo, é imprescindível que o Estado tenha aceitado previamente a competência da Corte. De acordo com os artigos 36 e 37 do seu Estatuto, isso pode ser feito de três formas: i) dois países podem, de comum acordo, decidir submeter um contencioso à Corte para que ela delibere e decida a respeito, ii) um tratado assinado por dois países pode estipular que em caso de controvérsia, ela seja dirimida pela CIJ e, por fim, iii) os países podem aceitar a cláusula de jurisdição obrigatória. Nesse último caso, quando um Estado aceita a cláusula facultativa de jurisdição obrigatória prevista no artigo 36 S 2 , entra para um rol de países que podem demandar e ser demandados perante a Corte em título de reciprocidade sem ter que pedir permissão prévia à outra parte. ${ }^{14}$

O intuito original era que todos os Estados membros da Corte automaticamente aceitassem a cláusula de jurisdição obrigatória da Corte, mas isso não foi possível devido à descrença da URSs: a delegação soviética acreditava que a jurisdição internacional não passava de mais uma instituição liberal a serviço dos países capitalistas e defendia que a aceitação de sua competência fosse feita individualmente de forma facultativa. ${ }^{15}$

Portanto, observa-se que a criação da CIJ foi fruto de um longo e conturbado processo histórico. Desde que a ideia de se criar um tribunal internacional de justiça fora proposta em 1899, foi preciso meio século de história, duas guerras mundiais e mais de 60 milhões de mortos para que o projeto se tornasse uma realidade. Não obstante esse fato, há décadas o

\footnotetext{
12 Singh, The role and record..., op. cit., p. 43. op. cit., p. 161 e s.

14 Lissitzyn, The International Court of Justice..., op. cit., p. 62.

15 Abi-Saab, "The International Court...”, op. cit.
}

13 Abi-Saab, Georges, "The International Court as the World Court", in lowe, Vaughan \& Malgosia, Fitzmaurice (Orgs.), Fifty years of the International Court of Justice, Cambridge University Press, New York, 2008, p. 4. V. também Menezes, Tribunais internacionais..., 
Brasil vem se recusando a aderir à cláusula de jurisdição obrigatória prevista no artigo 36 \2. No próximo capítulo, tentar-se-á entender o porquê disso.

\section{A posição do Brasil}

O Brasil tem sido bastante lacônico quanto aos motivos que o impelem a rejeitar a cláusula de jurisdição obrigatória. O país tem dito apenas que prefere se valer dos meios diplomáticos de resolução de controvérsias, recorrendo à arbitragem internacional quando necessário. ${ }^{16}$ Para se entender o que isso significa, deve-se tomar como ponto de partida o artigo $33 \int 1$ da carta da ONU.

Ao proibir a utilização da força em âmbito internacional, a Carta de São Francisco determina que a solução pacífica de controvérsias seja a regra geral a ser seguida pelos Estados para resolver os seus problemas. O capítulo VI da Carta dispõe sobre a matéria e seu artigo 33 \ 1 lista uma série de meios pelos quais as controvérsias podem ser resolvidas pacificamente: "As partes em uma controvérsia, que possa vir a constituir uma ameaça à paz e à segurança internacionais, procurarão, antes de tudo, chegar a uma solução por negociação, inquérito, mediação, conciliação, arbitragem, solução judicial, recurso a entidades ou acordos regionais, ou a qualquer outro meio pacífico à sua escolha".

Há dois pontos importantes que devem ser salientados a respeito do dispositivo legal acima. Em primeiro lugar, segundo a jurisprudência pacífica da CIJ, o termo "controvérsia" não se remete apenas aos dissídios que possam constituir uma ameaça à paz internacional. ${ }^{17}$ Portanto, qualquer oposição de interesses ou teses jurídicas entre Estados pode ser considerada uma controvérsia internacional, mesmo que ela não afete em nada a segurança internacional.

Em segundo lugar, não há hierarquia entre os meios de solução pacífica de controvérsia, podendo, de regra, os Estados escolherem quais meios preferem usar em determinado caso concreto. Quanto à via judicial de solução de controvérsias por meio da CIJ, essa opção desde 1948, tem sido eliminada quase por completo.

16 Rezek, J. Francisco, Direito internacional público, $9^{\circ}$ ed., Saraiva, São Paulo, 2002, p. 351.

17 Mazzuoli, Valério O., Curso de direito internacional público, $2^{\circ}$ ed., Revista dos Tribunais, São Paulo, 2007, p. 821. Menezes, Tribunais internacionais..., op. cit., p. 100 e s. 
Em 1945, quando o Brasil ratificou o Estatuto da CIJ, aderiu à cláusula de jurisdição obrigatória sob uma reserva temporal. A adesão seria válida somente por um exíguo espaço de tempo, depois do qual teria que ser renovada através de nova declaração. ${ }^{18}$ Infelizmente, isso não foi feito após 1948, quando a declaração original perdeu sua eficácia. ${ }^{19}$ Desde então, o país tem reiteradamente se recusado a aderir à cláusula de jurisdição obrigatória.

O mais surpreendente de tudo isso é que a cláusula em tela foi concebida justamente pela delegação brasileira durante a elaboração do Estatuto da Corte. ${ }^{20}$ Durante a fase inicial de criação, o intuito era que a sua jurisdição fosse compulsória para todos os países que ratificassem seu tratado constitutivo. Dessa forma, quando um país membro da ONU levasse outro à Corte, ele já saberia que a outra parte havia aceitado a jurisdição contenciosa do tribunal.

Todavia, a adoção dessa proposta encontrou forte resistência por parte das grandes potências que preferiam um sistema de aceitação de competência caso a caso, similar àquele empregado na arbitragem internacional, no qual ambos os países devem dar seu consentimento mútuo cada vez que firmarem o compromisso arbitral. ${ }^{21}$ A delegação brasileira liderada por Raul Fernandes propôs então um meio termo. ${ }^{22}$ Para os países reticentes a aceitar a competência compulsória da Corte, ela poderia ser determinada caso a caso, sempre contando com a anuência prévia das partes, como ocorre com a arbitragem internacional. Já para os países que quisessem aceitar a competência contenciosa da Corte, isso poderia ser feito por meio da cláusula de jurisdição obrigatória.

O substrato essencial deste dispositivo seria a reciprocidade, pois somente os países que subscrevessem a cláusula de jurisdição obrigatória poderiam se valer dela. Sempre que um Estado membro acionasse outro Estado membro signatário dessa cláusula, ambos já saberiam de antemão que a Corte teria competência para adjudicar a disputa, sem a necessidade

18 Rosenne, Shabtai, The Court and the United Nations, Koninklijke Brill NV, Leiden, 2006, p. 788.

19 Rosenne, Shabtai, An International Law miscellany, Martinus Nijhoff Publishers, Dordrecht, 1993, p. 16.

20 Singh, The role and record..., op. cit., p. 17.

21 Ibíd., p. 701.

22 Rosenne, The Court and the United Nations, op. cit., p. 701. 
de obter a permissão prévia das partes envolvidas. Apesar desse fato, após um curto período de adesão, como foi dito acima, a declaração brasileira de anuência à cláusula de jurisdição obrigatória perdeu eficácia em 1948. Desde então, ela não foi mais renovada, deixando o Brasil à margem do mais importante tribunal internacional da atualidade.

Contudo, é de se observar que desde 1948, o país passou por incríveis transformações. Ao todo foram três constituições diferentes e após um longo período de autoritarismo houve um retorno à democracia na década de 1980. Com a carta de 1988, o Brasil se inseriu no movimento neoconstitucionalista adotando uma constituição democrática, receptiva ao direito internacional, imbuída de força normativa, com eficácia e aplicabilidade direta e recheada de princípios referentes às garantias de direitos fundamentais.

Seu engajamento com o direito internacional pode ser depreendido de uma série de seus dispositivos. $\mathrm{O}$ artigo $4^{\circ}$ lista entre os princípios das relações internacionais do Brasil: a cooperação entre os povos para o progresso da humanidade, a solução pacífica dos conflitos, a prevalência dos direitos humanos, a autodeterminação dos povos, a não intervenção e a defesa da paz. Já o artigo $5^{\circ}, \$ 3$ da CF/88 alça os tratados internacionais referentes aos direitos humanos aprovados em cada casa do Congresso Nacional, em dois turnos, por três quintos dos votos, à categoria de emenda constitucional. No mesmo diapasão, o artigo $5^{\circ}, \$ 4$ da CF/88 aceita a jurisdição do Tribunal Penal Internacional.

Ao mesmo tempo que a Constituição valoriza o direito internacional público, o Brasil reluta em aderir à cláusula de jurisdição obrigatória da CIJ. A preferência acordada com os meios diplomáticos e com a arbitragem internacional não deveria invalidar a opção pela via judicial, que seria mais uma importante via de acesso para a pacificação de conflitos. Além de ser contrária aos princípios da sua carta magna, a posição brasileira referente à CIJ também macula a sua imagem internacional. Ao mesmo tempo em que o Brasil se apresenta ao mundo como uma potência regional em ascensão, liderando a missão de paz no Haiti e pleiteando uma vaga permanente no Conselho de Segurança da ONU, adota uma atitude incompreensível no que tange à mais importante instância internacional.

Ao agir dessa forma, o Brasil segue o péssimo exemplo da França e dos EuA. Outrora signatários da cláusula de jurisdição obrigatória, ambos os países decidiram denunciá-la. É importante estudar as razões que fundamentaram a descrença desses países na CIJ para comparar com a situação do Brasil. 


\section{Os exemplos da França e dos Estados Unidos}

Paris decidiu abandonar a cláusula de competência obrigatória após o deslinde do caso Nova Zelândia \& Austrália vs. França de $1974 .{ }^{23}$ Potência nuclear, a França deflagrou, na década de 1960, um extenso programa de testes atômicos para estudar o potencial bélico de seu arsenal. ${ }^{24}$ Entretanto, para resguardar sua população dos efeitos nefastos da radiação, os franceses realizavam seus testes atômicos de caráter atmosférico no Pacífico Sul, onde inúmeros artefatos nucleares foram detonados em suas ilhas paradisíacas. Entretanto, não é de se surpreender que nações não nucleares tais como a Austrália e Nova Zelândia se insurgissem contra o programa francês. Afinal de contas, seriam eles os Estados afetados pelos efeitos colaterais da radiação disseminada na região. Durante toda a década de 1960, esses países se opuseram à política francesa de testes nucleares no Pacífico. Em 1972, tendo esgotado todas as vias diplomáticas de negociação e não obtendo grande resultado através das resoluções aprovadas na Assembleia Geral da ONU, eles decidiram acionar a França perante a CIJ.

A Austrália e a Nova Zelândia argumentaram que as ações francesas contrariavam uma série de dispositivos do direito internacional, exigindo que a Corte se posicionasse a respeito desse assunto e instruísse o Estado francês a abandonar imediatamente seu programa de testes nucleares no Sul do Pacífico. Quando o processo ainda estava nos estágios iniciais, a França anunciou publicamente que decidira abandonar seu programa nuclear de testes, conforme a exigência dos autores da ação. ${ }^{25}$ Em meio ao furor político e social ocasionado pelo iminente julgamento a ser realizado e já na expectativa de obter uma sentença contrária aos seus interesses, a França decidiu minimizar suas perdas, anuindo integralmente ao pedido feito pelos autores da ação. Consegui-se finalmente obter através da CIJ o que havia sido impossível lograr por meio de negociações diplomáticas e das pressões políticas aplicadas pela Assembleia Geral das Nações Unidas.

O posicionamento adotado pela CIJ, nesse caso, indicava que o tribunal estava preparado para contrariar abertamente os interesses de um

23 Distefano, Giovanni \& Buzzini, Gionata P., Bréviaire de jurisprudence internationale. Les fondamentaux du droit international public, Bruylant, Bruxelles, 2005, p. 491.

24 Elias, Taslim, The International Court of Justice and some contemporary problems, Martinus Nijhoff Publishers, Dordrecht, 1989, p. 101.

25 Ementa oficial da decisão do Tribunal disponível no Site oficial da CIJ, em http:/ / www. icj-cij.org/docket/files/59/6161.pdf, acesso em 18/09/14. 
membro permanente do Conselho de Segurança em prol da defesa do direito internacional, da proteção ao meio ambiente e dos interesses de duas nações que não dispunham de outros meios para se defender das ações de uma potência nuclear. Há de se observar também que isso foi feito durante a Guerra Fria, quando qualquer tema referente à tecnologia nuclear era um assunto nevrálgico da política internacional. Por outro lado, houve um alto preço a se pagar por essa atitude independente e corajosa da Corte: a França abandonou a jurisdição obrigatória da CIJ em 1974. ${ }^{26}$ A decisão do Presidente francês foi motivada pelo não respeito da reserva da França emitida na sua declaração de aceitação da competência da Corte, na base do artigo $36 \$ 2$, que excluía as lides referentes às atividades vinculadas à defesa nacional. ${ }^{27}$ A quem critique a posição adotada pela Corte e responsabilize a denúncia da cláusula de jurisdição obrigatória à suposta falta de sensibilidade do tribunal para com os interesses geopolíticos de Paris. ${ }^{28}$

É realmente difícil não perceber o quanto falacioso é esse argumento. Se a título de não contrariar a França, a CIJ ignorasse a ilegalidade de seus atos e se recusasse a ordenar a paralisação de testes nucleares em ilhas paradisíacas, qual seria a legitimidade desse tribunal? Abandonar a Austrália e a Nova Zelândia, mesmo quando todo o direito internacional lhes assistia, seria o mesmo que transformar a CIJ em mais um órgão burocrático dedicado apenas a dar um semblante legal aos desígnios das grandes potências, independentemente do direito ou princípios aplicáveis. Aí sim, seria impossível para qualquer país em desenvolvimento acreditar na imparcialidade deste órgão jurisdicional. Portanto, foi essa a razão que motivou a renúncia francesa à cláusula de jurisdição obrigatória da Corte. É imprescindível que o Brasil, signatário do Tratado de Tlaleloco que proscreve a utilização de armas nucleares na América Latina e no Caribe, não se olvide deste caso e saiba qual exemplo ele está seguindo atualmente.

Seguindo os passos da França, Washington também decidiu abandonar a cláusula de jurisdição obrigatória após o deslinde do caso Nicarágua vs. EUA de $1984 .{ }^{29}$ Para compreender as complexidades deste caso é

\footnotetext{
26 Posner, Eric A., "Is the International Court of Justice biased?", Journal of Legal Studies, 2005, 34, (599), p. 7.

27 Brichambaut, M. P. de; Dobelle, J.-F.; Coulée, F., Leçons de droit international public, $2^{\circ}$ ed., Presses de Sciences Po et Dalloz, Paris, 2011, p. 402.

28 Posner, Eric A., "The decline of the International Court of Justice", in Voight, Stefan (Org.), International conflict resolution, New York, 2006, p. 23.

29 Distefano \& Buzzini, Bréviaire de jurisprudence internationale..., op. cit., p. 639.
} 
imprescindível conhecer seu contexto histórico. A Nicarágua é um pequeno país de 6 milhões de habitantes localizado na América Central. Sua história durante o século Xx não diferiu muito daquela dos demais países da região, sendo um misto de autoritarismo, exclusão social e intervencionismo norte-americano. ${ }^{30}$ Após mais de 40 anos de uma ditadura corrupta e sanguinolenta, as forças políticas de esquerda insurgiram contra o ditador Somoza. Seguindo a sua tradição intervencionista oriunda da Doutrina Truman de contenção do comunismo, os EUA iniciaram uma série de operações subversivas organizadas pela CIA: criou notadamente um grupo chamado de Contra no intuito de derrubar o novo governo. Desde sua gênese, ele foi armado e financiado pelo governo dos EUA.

Foi em meio a todo esse contexto histórico que o Estado da Nicarágua acionou os EUA perante a CIJ por terem os norte-americanos abertamente financiado e armado os Contra. Dentro da perspectiva distorcida da Guerra Fria, os EUA acreditavam que se opor aos Sandinistas era o mesmo que se opor à expansão do comunismo na América Latina. ${ }^{31} \mathrm{O}$ Estado norteamericano ficou irado com a ação da Nicarágua e foi logo argumentando perante os juízes da Corte de Haia que eles não dispunham de competência para admitir esse caso, haja vista que os EUA estavam exercitando seu direito à legítima defesa do Estado democrático de direito dos países vizinhos, em nome dos princípios da segurança coletiva e da soberania. ${ }^{32}$

A CIJ, no entanto, não se mostrou convencida. Não somente admitiu o caso como acabou decidindo em favor do autor, condenando os EUA a pagarem uma reparação por ter violado direitos humanos, invadido o território da Nicarágua e desrespeitado a sua soberania. ${ }^{33}$ Foi então que a maior potência do planeta, tendo sido legalmente derrotada e publicamente humilhada por um simplório país da América Central, resolveu abandonar a cláusula de jurisdição obrigatória da Corte. ${ }^{34}$

Há aqueles que questionam a atuação do tribunal de Haia neste caso e acreditam piamente que este cometeu um enorme equívoco ao decidir

30 Keylor, William R., The twentieth century world: an international history, $2^{\circ}$ ed., Oxford University Press, New York, 2004, p. 403.

31 Kissinger, Henry, Diplomacy, Simon \& Schuster, New York, 1994, p. 774.

32 Posner, "The decline...”, op. cit., p. 23.

33 Muller, A. S. \& Thuranszky, J. M., The International Court of Justice: its future role after fifty years, Martinus Nijhoff Publishers, Haia, 1997, p. 58.

34 Posner, "Is the International Court of Justice biased?", op. cit., p. 9. 
em favor da Nicarágua. De acordo com essa linha de raciocínio, a Corte deveria ter reconhecido as suas limitações políticas e ter se eximido de julgar os EUA nessa causa. ${ }^{35}$ Ao utilizar esse caso como um palanque para fazer média com os países em desenvolvimento, a Corte só teria irritado a maior potência do mundo, fazendo com que ela abandonasse o tribunal, não muito diferente do que ocorrera com a França. Até o final do processo, os EUA questionaram a imparcialidade da Corte. ${ }^{36}$

Mais uma vez retoma-se o argumento apresentado anteriormente. Se a título de se apaziguar os interesses geopolíticos do EUA, a CIJ se mantivesse silente e passiva perante o verdadeiro estupro da soberania nicaragüense, qual seria a legitimidade desse tribunal? Abandonar a Nicarágua, mesmo quando todo o direito internacional lhe assistia, seria o mesmo que transformar a CIJ em mais um órgão burocrático dedicado a carimbar os desígnios das grandes potências de forma subserviente e acrítica.

Pensar que o mais importante tribunal do sistema internacional pudesse agir de tal forma seria um escárnio para o direito internacional e um despautério para o conceito de justiça. No caso Nicarágua, a Corte decidiu contra os EUA mesmo tendo ciência plena de que sua decisão acarretaria profundas consequências políticas. Não obstante esse fato, ela não hesitou em defender o direito internacional público. ${ }^{37}$

Para um país como o Brasil que sempre se arvorou a defender a autodeterminação dos povos, a não intervenção e a igualdade entre os Estados, princípios entronizados no artigo 4 da Constituição de 1988, deve-se ter em mente qual exemplo ele vem decidindo seguir. A pretensa preferência por meios diplomáticos não pode servir de subterfúgio para se elidir por completo a via de solução judicial dos conflitos internacionais em nome de interesses geopolíticos contrários ao direito internacional público.

Contudo, a França e os EUA não foram as únicas vozes que se insurgiram contra a Corte sediada na Holanda. Devido a sua disposição em defender o direito internacional mesmo em face aos interesses geopolíticos de Estados poderosos, a CIJ contraiu muitos inimigos ao longo dos anos. Vozes as mais variadas se insurgiram contra a Corte, desferindo ataques virulentos no intuito de esvaziar a instituição e minar a sua atuação. Afinal, o Brasil não é único país a desdenhar a Corte. Atualmente, dos 193

35 Posner, "The decline...", op. cit., p. 23.

36 Pomerance, The United States..., op. cit., p. 343.

37 Abi-Saab, "The International Court...”, op. cit., p. 6. 
Estados membros da ONU, apenas 71 figuram no rol de países que aceitam a jurisdição obrigatória da Corte. ${ }^{38}$ Isso se deve à receptividade dada aos argumentos falaciosos apresentados por aqueles que descrêem tanto do direito internacional, quanto na missão da Corte. É importante rebater o que esses detratores têm a dizer, pois suas críticas não se sustentam nos fatos, como será visto a seguir.

\section{Análise crítica dos argumentos dos detratores da CIJ}

Durantes seus 68 anos de atuação, muitos foram os detratores que se insurgiram contra a CIJ, criticando a sua jurisprudência e proclamando a sua suposta derrocada. ${ }^{39}$ Muitos desses críticos tendem a vislumbrar o sistema internacional como sendo eminentemente anárquico, devido à inexistência de um poder centralizado que faça cumprir as normas de direito internacional. ${ }^{40}$ Para eles, o sistema internacional atual não se difere muito do estado de natureza descrito por Hobbes em sua obra clássica, o Leviathan. ${ }^{41}$ Nele, o Estado seria o lobo do Estado. Esses adeptos do Realismo, como Eric Posner, ${ }^{42}$ dedicam-se incansavelmente a desconstruir o projeto kantiano de soerguimento do direito internacional face à triste realidade hobbesiana da política internacional. ${ }^{43}$ Segundo o professor de Direito da Universidade de Chicago, a análise da atuação da CIJ deveria nos remeter a uma derradeira conclusão: o tribunal fracassou amargamente.

Detratores como Posner geralmente se valem de dois argumentos para justificar a renúncia da cláusula de jurisdição obrigatória: i) a corte carece de imparcialidade e, ii) ela entrou em franco declínio durante a segunda metade do século Xx, tornando-se uma instituição decrépita. Para convencer o governo brasileiro a modificar a sua atual postura é imprescindível expor a debilidade dos argumentos acima.

\footnotetext{
38 Site oficial da CIJ, em http://www.icj-cij.org/jurisdiction/index.php?p1=5\&p2=1\&p3=3, acesso em 23/01/15. A Itália aderiu em 25/11/14 e o Reino Unido em 31/12/14.

39 Abi-Saab, "The International Court...", op. cit., p. 4.

40 Baylis, J. \& Smith, S., The globalization of word politics, $3^{\mathrm{a}}$ ed., Oxford University Press, New York, 2006, p. 169.

41 Hobbes, Thomas, Leviathan, Dover Publications, London, 2006, p. 134.

42 Posner, "The decline...", op. cit., p. 1.

43 Baylis \& Smith, The globalization..., op. cit., p. 169.
} 
Atacar a imparcialidade da Corte é assestar um golpe de morte no seu coração pulsante. É comumente aceito no meio jurídico que a imparcialidade do magistrado é um dos pré-requisitos basilares à prestação da tutela jurisdicional. Um juiz imparcial é aquele que se mantém equidistante das partes do processo, decidindo a causa ao aplicar o direito existente ao fato concreto, sem conceder prerrogativas especiais a nenhuma das partes por razões particulares de preferência pessoal. A partir do momento em que se questiona a imparcialidade do juiz, abre-se a possibilidade à parte agravada de pedir seu afastamento e substituição para se garantir a higidez do processo e a justiça da decisão final. A independência constitui também o alicerce da justiça e da magistratura internacionais. Ao conceito de independência é normalmente associada a ideia de que o juiz deve exercer suas funções sem sofrer ingerência ou influência indevidas de origem exterior à jurisdição, como intromissões do Estado de origem ou de residência. ${ }^{44} \mathrm{~A}$ doutrina internacional, ciente de que favorecer a independência e a imparcialidade da magistratura internacional tem uma repercussão direta sobre a legitimidade e a eficácia dos processos judiciários internacionais, redigiu um projeto de um instrumento convencional universal que estabelece as garantias necessárias para assegurar standards equivalentes a todas as jurisdições internacionais, chamado "Princípios de Burgh House". ${ }^{45}$ Aliás, as exigências relativas à competência dos membros da jurisdição constam nos primeiros artigos do Estatuto. Portanto, sendo a imparcialidade do juiz uma pedra de toque fundamental de qualquer Estado democrático de direito, há quem questione a sua existência no âmbito da CIJ. ${ }^{46}$

Segundo seus críticos, não se pode dizer que a Corte seja imparcial quando seus juízes tendem a ser parciais a seus Estados de origem e aos demais Estados que ao seu se assemelham. Ao se analisar a jurisprudência produzida nos primeiros 55 anos de atividade da Corte, constatou-se que em $90 \%$ dos casos em que um juiz votou em um processo envolvendo seu Estado de origem, o voto foi a seu favor. Percebe-se também que os juízes

44 Malenovsky, Jiri, "Les opinions séparées et leurs répercussions sur l'indépendance du juge international", ACDI, 2010, 3, p. 27, em http://revistas.urosario.edu.co/index.php/ acdi/article/view/1424/1304, acesso em 11/02/15.

45 ILA Study Group, The Burgh House principles on the independence of the international judiciary. Study Group for the International Law Association on the Practice and Procedure of International Courts and Tribunals, Burgh House, London, 2004, em http:/ / www.pict-pcti.org/activities/Burgh\%20House \%20French.pdf, acesso em 11/02/15.

46 Posner, "Is the International Court of Justice biased?", op. cit., p. 28. 
oriundos de Estados democráticos tendem a votar em favor de Estados com regimes representativos enquanto os juízes oriundos de Estados autoritários tendem a votar a favor de outros Estados igualmente totalitários. Por fim, os juízes de Estados abastados tendem a votar em favor de Estados desenvolvidos, enquanto os juízes de Estados em desenvolvimento tendem a votar em favor dos Estados pobres. ${ }^{47} \mathrm{O}$ juiz do Tribunal de Justiça da União Europeia Malenovsky denuncia, por exemplo, a prevalência das considerações de ordem política nas modalidades de nomeação dos juízes internacionais: "Les gouvernements sont des organes profondément politiques et, par définition, font reposer leurs décisions sur des considérations d'ordre politique. L'exercice du choix des juges internationaux ne peutpas échapper non plus à cette logique simple". ${ }^{48}$ Vale sublinhar que os Estados, em 1945, aceitaram a criação de uma jurisdição permanente e universal somente depois que foi resolvida, de maneira preliminar, a questão da sua composição. ${ }^{49}$

Com base nas decisões proferidas em aproximadamente 106 casos decididos pela jurisdição internacional em um período de aproximadamente 50 anos, autores como o professor Posner concluem que os juízes não decidem os casos que lhe são trazidos de forma imparcial, sendo diretamente influenciados por sua nacionalidade e por demais características referentes ao seu Estado de origem. Todavia, o próprio autor admite que outros estudiosos descrevem essa tese como sendo "desdentada" ${ }^{50}$ Vejamos agora alguns argumentos que relativizam essas conclusões.

Quando a CIJ foi criada em 1946, determinou-se que o mais alto órgão jurisdicional de âmbito internacional seria composto por 15 magistrados indicados pelos Estados membros da ONU e aprovados tanto pela Assembleia Geral, quanto pelo Conselho de Segurança da ONU. ${ }^{51}$ Este poder de codecisão foi pensado para agradar tanto as pequenas e médias potências, que representam a maioria na Assembleia Geral, quanto as grandes potências, membros permanentes do Conselho de Segurança. Acordou-se também que cada magistrado seria eleito para um período

\footnotetext{
47 Ibíd.

48 Malenovsky, "Les opinions séparées...”, op. cit., p. 36.

49 Quoc Dinh, Daillier, Forteau \& Pellet, Droit international public, op. cit., p. 988.

50 Franck, Thomas, Fairness in International Law and institutions, $2^{\circ}$ ed., Oxford University Press, New York, 1995, p. 346.

51 McWhinney, Edward, The International Court of Justice and the Western tradition of International Law, Martinus Nijhoff Publishers, Dordrecht, 1987, p. 73.
} 
renovável de nove anos, sendo que um terço do tribunal seria renovado a cada três anos. Vedou-se expressamente a possibilidade de haver mais do que um juiz da mesma nacionalidade servindo na Corte, para se garantir a maior representatividade internacional possível..$^{52}$ Os membros da CIJ não são agentes governamentais; seu papel é de aplicar e interpretar o direito internacional e não defender os interesses da sua pátria. Para garantir sua independência, eles gozam das mesmas imunidades que os agentes diplomáticos. São inamovíveis e não podem exercer outra atividade profissional. ${ }^{53}$

Quanto ao critério de preenchimento desses cargos, adotou-se o mesmo sistema de distribuição geográfica empregado no Conselho de Segurança. Dessa forma, os cinco membros permanentes do Conselho de Segurança (EUA, Reino Unido, França, Rússia e China) são sempre representados na CIj e os demais dez juízes são escolhidos da seguinte forma: dois são provenientes da América Latina, três da África, dois da Ásia, um da Europa Oriental, dois da Europa Ocidental (incluindo-se nesse grupo o Canadá, a Austrália e a Nova Zelândia). Vejamos, por exemplo, o quadro de representação da CIJ em 2015, em função da área geográfica, além dos cinco juízes oriundos dos Estados membros permanentes do Conselho de Segurança: Brasil e México; Japão e Índia; Itália e Nova Zelândia; Eslováquia e Uganda, Marrocos e Somália. ${ }^{54}$

Apesar dos membros permanentes do Conselho de Segurança disporem de representação permanente na CIJ, seu privilégio não é excessivo, pois eles não detêm o poder de veto nesse órgão (art. 10 do Estatuto). ${ }^{55}$ Ou seja, as decisões proferidas pela Corte são tomadas com base na maioria absoluta dos magistrados, sendo que cada voto tem o mesmo peso. ${ }^{56}$

É importante observar que a partir do momento em que dois Estados concordam em submeter uma disputa ao processo de adjudicação da CIJ, eles abdicam da possibilidade de recorrer a outros meios para solucionar o contencioso. Esse tipo de cerceamento da soberania estatal só seria possível caso a CIJ fosse criada de tal forma que os próprios Estados pudessem fazer com que seus interesses nela fossem representados. Foi

52 Lissitzyn, The International Court of Justice..., op. cit., p. 50.

53 Quoc Dinh, Daillier, Forteau \& Pellet, Droit international public, op. cit., p. 989.

54 Dados colhidos no site oficial da CIJ.

55 Ibíd.

56 Mazzuoli, Curso de direito internacional público, op. cit., p. 846. 
por essa razão que as grandes potências obtiveram representação permanente no órgão.

Todavia, isso não quer dizer que a Corte seja um órgão burocrático a serviço dos interesses imperiais de determinados Estados. Mesmo que em um caso concreto, um juiz oriundo de determinado Estado decida sempre votar em favor dos seus interesses nacionais, ele terá de convencer pelo menos sete outros juízes de nacionalidades as mais diversas a seguir a sua linha de raciocínio para que a Corte como um todo vote a seu favor.

A composição da CIJ privilegia obviamente os representantes do pensamento jurídico ocidental em detrimento de outras famílias jurídicas. Existe outras jurisdições internacionais como, por exemplo, o Tribunal Internacional do Direito do Mar, no qual os "países da periferia" detêm proporcionalmente mais assentos. ${ }^{57}$ Porém, como pode ser depreendido do rol acima, mesmo que determinado juiz decida votar a favor de seu Estado de origem independentemente dos argumentos jurídicos apresentados, a composição do tribunal é suficientemente heterogênea para lidar com esse tipo de parcialidade individual. De acordo com o artigo 31 do Estatuto, sempre que um Estado for acionado perante a Corte sem nela tenha um juiz de sua nacionalidade, ele terá o direito de nomear um juiz ad hoc que comporá o tribunal somente naquele caso. ${ }^{58}$ Todavia, esse juiz ad hoc, uma vez designado, goza das prerrogativas e obrigações do juiz "permanente": pode se posicionar contra o Estado da sua nacionalidade, pois ele não é juridicamente seu representante. Os autores Brichambaut e Dobelle ${ }^{59}$ admitem, porém, que a experiência demonstra que o juiz ad hoc, por conhecer melhor seus problemas nacionais e seu sistema jurídico, adota normalmente uma posição favorável às pretensões do Estado que o nomeou. O magistrado internacional Malenovsky fala de "parenté d'esprit" ou de "union d'opinions" entre o juiz e o Estado da sua nacionalidade. ${ }^{60}$ No entanto, autores citam vários casos em que o juiz não defendeu a posição do país da sua nacionalidade. ${ }^{61}$

\footnotetext{
57 Menezes, Tribunais internacionais..., op. cit., p. 215.

58 Mazzuoli, Curso de direito internacional público, op. cit., p. 846.

59 Brichambaut, Dobelle \& Coulée, Leçons de droit international public., op. cit., p. 395 e s.

60 Malenovsky, "Les opinions séparées...”, pp. 36 e 38.

61 Quoc Dinh, Daillier, Forteau \& Pellet, Droit international public, op. cit., p. 991. Varella, Marcelo D., Direito internacional público,Saraiva, São Paulo, 2009, p. 432.
} 
Mais uma vez, eis aí um mecanismo, mesmo imperfeito, que visa lidar com possível parcialidade de juízes oriundos de determinados Estados, oferecendo um tratamento mais igualitário a todas as partes do processo. É significativo que o conceito de "repartição geográfica equitativa", que inspira a composição da Corte não figura no Estatuto que se contenta em se referir à necessidade de assegurar a representação das grandes formas de civilização e dos principais sistemas jurídicos do mundo (art. $\left.9^{\circ}\right) .{ }^{62}$ Portanto, não faz sentido dizer que a Corte carece de imparcialidade porque dispõe de vários mecanismos para lidar com o ocasional favoritismo que determinados juízes possam eventualmente demonstrar em favor dos seus Estados de origem.

Nota-se que o Brasil, apesar de não ser Estado membro da CIJ, pode se orgulhar de ter fornecido ao tribunal universal eminentes juristas como Filadelfo de Azevedo (1946), Levi Carneiro (1951), José Sette Câmara (1979), José Francisco Rezek (1997) e Antônio Augusto Cançado Trindade (juiz desde 2009). ${ }^{63} \mathrm{O}$ país poderia ainda usar o argumento da imparcialidade da Corte para legitimar sua recusa a assinar a cláusula de jurisdição obrigatória?

Quanto ao pretenso declínio da Corte, argumenta-se que o sinal mais alarmante da sua suposta derrocada seja a utilização, cada vez menor, das grandes potências. Tomando como base a atuação da Corte entre 1946 e 2004, Posner $^{64}$ divide esse espaço de tempo em três períodos de análise. Entre 1946 e 1965, as grandes potências apareceram como autores ou réus em $60 \%$ das ações da CIJ. Entre 1965 e 1985, esse número caiu para $50 \%$. Por fim, já entre 1985 e 2004, as grandes potências figuraram como autores em $13 \%$ das ações, mas apareceram como réus em quase $100 \%$ dos casos. Com base nesses dados, ele conclui que as grandes potências progressivamente perderam interesse na utilização da Corte, o que supostamente seria uma indicação clara de seu declínio.

Infelizmente, essa tese só parece ser crível caso se ignore as muitas transformações históricas que ocorreram no mundo, nesse período. Em 1946, a ONU tinha 51 membros originais, mas já em 2004 passou a contar com 193 Estados membros. O processo de descolonização ocorrido após

\footnotetext{
62 Brichambaut, Dobelle \& Coulée, Leçons de droit international public, op. cit., p. 395.

63 Varella, Direito internacional público, op. cit., p. 432. Sem esquecer que Ruy Barbosa foi nomeado no Palácio da Paz, em 1921, para o mandato inicial da CPIJ.

64 Posner, “The Decline...", op. cit., p. 7.
} 
a Segunda Guerra Mundial transformou praticamente todas as antigas colônias europeias na África e Ásia em Estados independentes. Tamanha foi a importância dessa transformação geopolítica que, em 1965, a ONU decidiu ampliar o Conselho de Segurança para incluir 15 e não apenas 10 Estados. Portanto, o surgimento de mais de 100 Estados independentes em menos de meio século certamente viria a afetar o perfil daqueles que utilizavam os serviços da CIJ por três razões. Primeiro, havendo um maior número de Estados no sistema internacional era de se esperar que a utilização da Corte por parte das grandes potências se diluísse. Segundo, é preciso lembrar que muitos dos Estados independentes recentemente criados, ainda em estágios primários de desenvolvimento, eles tinham que lidar com problemas que não mais afligiam as grandes potências. Por exemplo, muitos dos Estados recém-criados, especialmente os africanos, tinham uma série de disputas referentes aos seus limites territoriais. Ironicamente, o próprio Posner reconhece que dos 105 casos analisados pela CIJ até 2004, 33 deles, ou seja $31 \%$ se referiam a disputas territoriais, sendo de longe o tipo de caso mais freqüentemente adjudicado pelo tribunal. ${ }^{65} \mathrm{Em}$ terceiro lugar, não é de se surpreender que entre 1985 e 2004, as grandes potências figurassem como autores em 13\% das ações, mas aparecessem como réus em quase $100 \%$ dos casos.

A partir do momento em que o princípio da autodeterminação dos povos, previsto expressamente no tratado constitutivo da ONU, deixou de ser letra morta, os mais variados povos do mundo tiveram a oportunidade de começar a constituir seus próprios Estados. Pequenos países como o Djibouti acionaram grandes potências como a França em 2006, buscando pela via judicial uma solução a problemas que antes seriam insolúveis por qualquer outro meio. Vale lembrar que a França, membro permanente do Conselho de Segurança, apesar de não ser mais signatária da cláusula de jurisdição obrigatória da CIJ, aceitou voluntariamente a competência da Corte, como em 2003, quando foi acionada pela República Democrática do Congo, contestando sua lei penal de competência universal. ${ }^{66}$ Para muitos, esse deveria ser um sinal claro do êxito da CIJ em se adaptar às novas realidades geopolíticas do mundo, concedendo a povos historicamente mais fracos e oprimidos uma ocasião de confrontar Estados incomparavelmente mais fortes. Não é tão difícil perceber porque as grandes potências

\footnotetext{
65 Ibíd., p. 3.

66 Brichambaut, Dobelle \& Coulée, Leçons de droit international public, op. cit., p. 396.
} 
perderam paulatinamente o interesse na utilização da Corte. ${ }^{67}$ É natural que grandes potências como a França e os EUA se mostrem refratárias ao novo papel da Corte, pois a democratização da justiça internacional vem desencadeando uma diluição progressiva da influência dos Estados mais poderosos e isso deveria ser visto com bons olhos.

Diferentemente do Conselho de Segurança da ONU, as decisões da Corte são tomadas por maioria absoluta dos votos proferidos por seus 15 membros, sem que nenhum deles disponha do poder de veto. ${ }^{68} \mathrm{Na}$ impossibilidade de controlar a CIJ da mesma forma como controlam o Conselho de Segurança, alguns dos países em posição dominante optaram por obstar seu funcionamento e proclamar a pretensa derrocada da instituição.

Último argumento que poderia justificar a resistência do Brasil é a preocupação do governo em resguardar sua soberania. ${ }^{69} \mathrm{Com}$ efeito, o Brasil tece relações estremecidas com as jurisdições internacionais e regionais. Em retaliação contra a solicitação da Comissão Interamericana de Direitos Humanos (CIDH), mediante uma medida cautelar de suspensão da construção da barragem de Belo Monte até que sejam adequadamente consultados os povos indígenas por ela afetados, o governo brasileiro adotou medidas de protestação: retirou o seu embaixador da Organização dos Estados Americanos (OEA), suspendeu o pagamento da sua cota anual ao organismo, resolveu não mais apresentar seu candidato à CIDH e tomou a iniciativa de criar um grupo de trabalho para propor a reforma desta, no sentido de diminuir seus poderes de questionar os governos sobre violações. Essa posição retrógrada do governo brasileiro provocou a reação de intelectuais, de especialistas de direitos humanos e da sociedade civil nacional e internacional ${ }^{70}$ que o obrigou a reatar com o órgão no

67 Posner, "The Decline...", op. cit., p. 23.

68 Mazzuoli, Curso de direito internacional público, op. cit., p. 846.

69 Ler a opinião do embaixador e ex-membro da Assessoria Especial da Presidência da República, Patriota, Guilherme de A., "Dois pesos, duas medidas", Folha de São Paulo, 07/08/12, em http://www1.folha.uol.com.br/fsp/opiniao/59211-dois-pesos-duas-medidas.shtml, acesso em 25/01/15.

70 Ventura, Deisy; Piovesan, Flávia; Kweitel, Juana, "Sistema interamericano sob forte ataque", Folha de São Paulo, 07/08/12, em http://www1.folha.uol.com.br/fsp/opiniao/59213sistema-interamericano-sob-forte-ataque.shtml, acesso em 25/01/15. De Soussa Santos, Boaventura, "Oitava carta às esquerdas: as últimas trincheiras", Carta Maior, 04/09/12, em http://www.cartamaior.com.br/templates/colunaMostrar.cfm?coluna_id=5737, acesso em 04/09/12. 
ano seguinte. ${ }^{71} \mathrm{~A}$ CIDH não é o único exemplo que corrobora as difíceis relações entre o Brasil e as jurisdições internacionais. Após quatro anos de tergiversações, o país resolveu assinar e ratificar o Estatuto de Roma de 1998 que criou o Tribunal Penal Internacional (TPI), ${ }^{72}$ jurisdição de caráter permanente competente para julgar os indivíduos que cometeram crimes internacionais. Porém a incorporação de um dos principais diplomas internacionais de defesa dos direitos humanos na sua ordem jurídica nacional não significa uma relação totalmente apaziguada com a organização internacional: no mês de janeiro de 2015, o TPI decidiu suspender o maior país latino-americano... por falta de pagamento da sua contribuição, o que impede o país de votar, por exemplo, na escolha de novos juízes, sem falar do constrangimento político que isso significa. ${ }^{73}$

O que parece incoerente na posição do Brasil é o fato de ele ser membro de jurisdições internacionais que potencialmente são mais subversivas no que tange à ingerência direta nos assuntos internos do país, como a CIDH ou o TPI, e não ser membro da CIJ, jurisdição universal que, vimos acima, demonstrou sua independência e seu anseio em adotar decisões que não sempre favorecem os países em posição hegemônica.

Enfim, em prol da assinatura da cláusula de jurisdição obrigatória da última, é relevante notar que o Brasil reconhece indiretamente sua competência, posto que ela é prevista como meio de resolução de controvérsias em mais de 260 convenções bilaterais e multilaterais, ${ }^{74}$ das quais várias foram assinadas e ratificadas pelo Brasil, sobre temas como guerra, paz e terrorismo, proteção aos direitos humanos, luta contra o tráfico de entorpecentes ou direitos do autor. ${ }^{75}$

Afastados os argumentos dos detratores da CIJ, vejamos agora os argumentos em favor do reingresso do Brasil ao colo da principal jurisdição internacional.

71 Fleck, Isabel, "Brasil quer reatar com órgão que criticou Belo Monte", Folha de São Paulo, 07/08/12, em http://www1.folha.uol.com.br/fsp/mundo/112572-brasil-quer-reatar-com-orgao-que-criticou-belo-monte.shtml, acesso em 25/01/15.

72 Decreto 4.388 de 25/09/02, em http:/ /www.planalto.gov.br/ccivil_03/decreto/2002/ D4388.htm, acesso em 25/01/15.

73 Chade, Jamil, "Brasil perde direito de votar em Tribunal da ONU por falta de pagamento", O Estado de São Paulo, em http:/ /internacional.estadao.com.br/noticias/geral,brasil-perdedireito-de-votar-em-tribunal-da-onu-por-falta-de-pagamento,1623453, acesso em 25/01/15.

74 Brichambaut, Dobelle \& Coulée, Leģons de droit international public, op. cit., p. 397.

75 Ver a lista in Varella, Direito internacional público, op. cit., p. 435. 


\section{A CIJ e o fortalecimento do DIP}

Com base em tudo discutido até então, é temerário se justificar a renúncia da cláusula de jurisdição obrigatória apontando-se para o suposto declínio da Corte. Na realidade, os 60 anos da Corte simbolizam a ascensão da justiça internacional, acompanhada pelo desenvolvimento progressivo e paulatino do direito internacional público. Após a queda do muro de Berlim em 1989, a CIJ, segundo Brichambaut e Dobelle, ${ }^{76}$ recuperou seu prestígio. Sua autoridade moral é hoje inegável. A leitura das decisões da Corte é uma viagem na história diplomática do mundo. Ela resolveu contenciosos sobre conflitos territoriais oriundos da descolonização na África; sobre a delimitação de zonas de pesca ou espaços aéreos; sobre sequestros e atentados; sobre o meio ambiente ou genocídio. Hoje, são 14 processos pendentes no tribunal de Haia, ${ }^{77}$ o que pode parecer pouco, ${ }^{78}$ mas é, todavia, sem precedente e contrasta com a situação dos anos 19701980, na qual a Corte era acusada tanto pelos países do Terceiro Mundo, para usar a terminologia de outrora, por ser "conservadora", quanto pelos países ocidentais que a acusava de ser demais "terceiro-mundista". É significante o fato de as partes nos processos da Corte serem oriundas de todas as regiões do globo, inclusive da América latina. ${ }^{79}$ De modo geral, os autores lembram de maneira pertinente que a Corte foi implicada em algumas das mais graves crises políticas e diplomáticas das últimas décadas: confrontos armados entre países africanos da região dos Grandes Lagos; na ex-Iugoslávia nos anos 1990, entre a Rússia e a Geórgia em 2008. A CIJ, como qualquer jurisdição, constitui um excelente instrumento para acalmar uma crise, ultrapassar um impasse ou prevenir um conflito.

As decisões da Corte são obrigatórias para as partes da lide, definitivas e irrecorríveis. Reza o artigo $94 \mathrm{da}$ Carta da ONU que se uma das partes violar uma decisão do tribunal, a outra parte pode acionar o Conselho de Segurança (CS) que possui vários instrumentos para sancionar e pressionar o Estado refratário. Na prática, as decisões são quase todas respeitadas pelas partes. A doutrina identifica uma única tentativa de acionamento do

\footnotetext{
76 Brichambaut, Dobelle \& Coulée, Leçons de droit international public, op. cit., p. 408 e s.

77 Site da CIJ.

78 Distefano \& Buzzini, Bréviaire de jurisprudence internationale..., op. cit., p. IX: “[...] l'impact des décisions judiciaires et arbitrales est proportionné à leur rareté”.

79 Brichambaut, Dobelle \& Coulée, Leçons de droit international public, op. cit., p. 409 e s.
} 
CS, com base no artigo 94, pela Nicaragua, no dia seguinte da decisão de 1986, porém a adoção da resolução foi vetada pelos Estados Unidos. Mas no geral, são poucas as decisões cuja execução criou dificuldades, como lecionam Brichambaut e Dobelle. ${ }^{80}$ Recentemente, por exemplo, a jurisdição encerrou um conflito territorial marítimo secular, fruto da guerra do Pacífico (1879-1883), opondo o Peru ao Chile. ${ }^{81} \mathrm{Na}$ sua decisão do $27 / 01 / 13$, a Corte traçou uma nova linha da fronteira marítima no intuito de obter um "resultado equitativo", solução aceita por ambas as partes. Outro exemplo hodierno do papel da Corte na pacificação das relações internacionais: o Japão obedeceu finalmente, depois de quase 30 anos de violação da Convenção Internacional para a Regulamenação da Caça à Baleia, à injunção do tribunal internacional, acionado pela Austrália, de parar imediatamente seu pretendido programa de pesquisa Jarpa sobre as baleias no oceano Antártico. ${ }^{82}$ Enfim, dia 3 de fevereiro de 2015, a principal corte das Nações Unidas decidiu que nem a Sérbia nem a Croácia cometeram um genocídio durante a guerra de 1991-1995. ${ }^{83}$ Essa decisão, que encerra uma longa batalha jurídica e memorial entre Zagreb e Belgrade, não agradou o governo croata, porém o Primeiro-ministro, Zoran Milanovic, declarou "aceitá-la de maneira civilizada". ${ }^{84}$

Não é a teoria jurídica que negaria o papel essencial da jurisprudência na formação do direito. O conjunto das decisões e pareceres da CIJ é uma ferramenta extremamente importante na construção, identificação, interpretação e consolidação da normas internacionais. ${ }^{85}$ Teóricos reconhecem que a jurisprudência pode também se tornar um motor poderoso

\footnotetext{
80 Ibíd., p. 407 e s.

81 CIJ, Arrêt 27/01/14, "Différend maritime (Pérou c. Chili)", em http://www.icj-cij. org/docket/files/137/17931.pdf, acesso em 26/01/15.

82 CIJ, Arrêt 31/03/14, “Chasse à la baleine dans l'Antartique (Australie c. Japon)”, em http://www.icj-cij.org/docket/files/148/18137.pdf, acesso em 26/01/14.

83 CIJ, Arrêt 03/02/15, "Application de la Convention pour la prévention et la répression du crime de génocide. Croatie c. Serbie", em http:/ /www.icj-cij.org/docket/files/118/18423. pdf

84 Maupas, Stéphanie, "Génocide : la justice internationale renvoie Serbes et Croates dos à dos”, Le Monde, 03/02/15, em http:/ / abonnes.lemonde.fr/europe/article/2015/02/03/ genocide-la-justice-internationale-renvoie-serbes-et-croates-dos-a-dos_4569187_3214. html, acesso em 05/02/15.

85 Abi-Saab, George, Cours général de droit international public, RCDAI, Haia, 1987, v. 207, p. 244.
} 
da evolução das regras do direito, o que torna imprescindível a presença de todos os Estados de todos os sistemas jurídicos na jurisdição para que eles possam influenciar as decisões que servirão de opinio juris dos sujeitos de direito internacional. ${ }^{86}$

O exercício da competência consultiva da CIJ ilustra perfeitamente esse fenômeno, pois a Corte também contribui enormemente para a manutenção da paz internacional através da edição de pareceres sobre direito internacional público. Esses pareceres ajudam a esclarecer as regras de convívio do sistema internacional e contribuem para a manutenção da paz. ${ }^{87}$ O caso Folke Bernadotte julgado em 1948, ao outorgar a personalidade jurídica internacional à organização internacional, ilustra perfeitamente este ponto de vista. ${ }^{8}$

Um país como o Brasil que pretende se tornar o líder regional incontornável, que quer atuar ativamente em todos os foros internacionais, que participa de operações de paz, que possui riquezas naturais cobiçadas, que prega o multilateralismo pode continuar fora do principal foro de solução de controvérsias sobre a paz? Portanto, a adesão brasileira à cláusula de jurisdição obrigatória significaria uma forte demonstração do comprometimento brasileiro para com a democratização da justiça internacional, a solução pacífica de conflitos e o fortalecimento do direito internacional público.

\section{Conclusão}

Desde que a ideia de se criar uma corte internacional de justiça foi proposta em 1899, foi preciso meio século de história, duas guerras mundiais e mais de 60 milhões de mortos para que o projeto se tornasse uma realidade. Conquanto este fato, o Brasil vem se recusando a aderir, desde 1948, à cláusula de jurisdição obrigatória da Corte.

São inúmeras as contradições que assolam a posição brasileira nessa questão. O país reluta em aderir a uma cláusula que fora originalmente concebida pela própria delegação brasileira liderada por Raul Fernandes durante a elaboração do Estatuto. Além disso, em que pese

\footnotetext{
86 Distefano \& Buzzini, Bréviaire de jurisprudence internationale..., op. cit., p. x.

87 Lissitzyn, The International Court of Justice..., op. cit., p. 3.

88 Ibíd., p. 212. Rosenne, Shabtai, The World Court: what it is and how it works, $6^{\circ}$ ed., Brill Academic Publishers, Leiden, 2003, p. 131.
} 
ter uma constituição democrática altamente receptiva ao direito internacional, o país insiste em não reconhecer a competência contenciosa da corte sob o pretexto de que prefere lidar com suas controvérsias pela via diplomática.

Ao agir dessa forma, o Brasil segue o péssimo exemplo da França e dos EUA. Na realidade, a pretensa preferência por meios diplomáticos não pode servir de subterfúgio para se elidir por completo a via de resolução judicial dos conflitos internacionais em nome de interesses geopolíticos contrários ao direito internacional público. A França abandonou a CIJ em prol da sua política fratricida de testes nucleares e os EUA por conta de sua política intervencionista na América Central. Para um país como o Brasil que sempre se vangloriou da responsabilidade de defender a autodeterminação dos povos, a não intervenção, a igualdade entre os Estados e a defesa da paz, princípios consagrados no artigo $4^{\circ}$ da Constituição da República de 1988, deve-se ter em mente qual exemplo ele vem decidindo seguir.

Portanto, é imprescindível que o Brasil não se una ao coro de vozes que atacam incessantemente a Corte. Devido a sua disposição em defender o direito internacional, mesmo em face dos interesses geopolíticos de Estados poderosos, a CIJ contraiu muitos inimigos ao longo dos anos. Vozes as mais variadas se insurgiram contra a Corte, desferindo ataques virulentos no intuito de esvaziar a instituição e minar sua atuação.

Contudo, os argumentos empregados para justificar a renúncia da cláusula de jurisdição obrigatória carecem de respaldo nos fatos. Quanto à pretensa imparcialidade da Corte, viu-se que a CIJ dispõe de vários mecanismos para lidar com a parcialidade individual que determinados juízes possam, eventualmente, demonstrar em favor dos seus Estados de origem. Quanto ao seu pretenso declínio devido ao gradual esvaziamento por parte das grande potências, essa tese só é crível caso se ignore o processo de descolonização ocorrido após a Segunda Guerra Mundial. Ao se adaptar às novas realidades geopolíticas do mundo, a CIJ concedeu a povos historicamente mais fracos e oprimidos uma oportunidade de confrontar Estados incomparavelmente mais fortes, permitindo que eles obtivessem, pela via judicial e pacífica, uma solução para problemas que antes seriam insolúveis por qualquer outro meio.

$\mathrm{Na}$ realidade, os últimos 50 anos simbolizam a ascensão da justiça internacional, acompanhada pelo desenvolvimento progressivo e paulatino do direito internacional público.

Por fim, em que pese a simplicidade do presente artigo, deve-se observar que ele está inserido em um contexto histórico maior. Há vários 
séculos está em curso uma batalha titânica pelo destino da humanidade, na qual digladiam dois campos diametralmente opostos. De um lado, há os kantianos que acreditam na manutenção da paz através da justiça institucionalizada. Seu lema está escrito na própria fachada do palácio da paz em Haia onde se pode ler: pacis tutela apudjudicem, a manutenção da paz com justiça. Essa, em última instância, é a melhor descrição da árdua missão que paira diante da CIJ, o mais importante órgão judicial da ONU, criado para oferecer uma via judicial para a resolução pacífica de controvérsias estatais e contribuir para o desenvolvimento do direito internacional.

Por outro lado, há os hobbesianos que acreditam na manutenção da paz através da guerra e a utilização da força nas relações internacionais. Para eles, o lema a ser seguido é: si vis pacem, para bellum, se desejas a paz, prepara-te para guerra. Conta-se entre seus seguidores figuras históricas de peso tais como Alexandre o Grande, Gengis Khan, Napoleão e Adolph Hitler. No início do século XXI, é imprescindível que cada Estado reflita cuidadosamente acerca dessa questão, pois todos terão que escolher a qual campo desejam pertencer.

No caso do Brasil, ao mesmo tempo em que o país se apresenta ao mundo como uma potência regional em ascensão, adota uma atitude refratária à mais importante corte internacional da atualidade. Portanto, é imprescindível que o Brasil se reconcilie com a jurisdição internacional e entregue ao Secretário Geral da ONU a sua declaração de adesão à cláusula de jurisdição obrigatória.

\section{Referências bibliográfícas}

Abi-Saab, Georges, "The International Court as the World Court", in Lowe, Vaughan \& Malgosia, Fitzmaurice (Orgs.), Fifty years of the International Court of Justice, Cambridge University Press, New York, 2008.

Abi-Saab, Georges, Cours général de droit international public, RCDAI, Haia, 1987, v. 207, p. 244.

Amr, Mohamed S., The role of the International Court of Justice as the principal judicial organ of the United Nations, Kluwer Law International, Haia, 2003.

Araripe, Luiz de Al., “Tratado de Versalhes”, in Magnoli, Demétrio (Org.), História da paz, Contexto, São Paulo, 2008.

Baylis, J. \& Smith, S., The globalization of word politics, $3^{a}$ ed., Oxford University Press, New York, 2006. 
Brichambaut, Marc Perrin de; Dobelle, Jean-François \& Coulée, Frédérique, Leçons de droit international public, $2^{\circ}$ ed., Presses de Sciences Po et Dalloz, Paris, 2011.

Chade, Jamil, "Brasil perde direito de votar em Tribunal da ONU por falta de pagamento", O Estado de São Paulo, em http:/ / internacional.estadao. com.br/noticias/geral,brasil-perde-direito-de-votar-em-tribunal-daonu-por-falta-de-pagamento,1623453, acesso em 25/01/15.

Corte Internacional de Justicia (CIJ), site oficial, em http://www.icj-cij. org/docket/files/59/6161.pdf, acesso em 08/07/12.

De Soussa Santos, Boaventura, "Oitava carta às esquerdas: as últimas trincheiras", Carta Maior, 04/09/12, em http://www.cartamaior. com.br/templates/colunaMostrar.cfm?coluna_id=5737, acesso em 04/09/12.

Distefano, Giovanni \& Buzzini, Gionata P., Bréviaire de jurisprudence internationale. Les fondamentaux du droit international public, Bruylant, Bruxelles, 2005.

Elias, Taslim, The International Court of Justice and some contemporary problems, Martinus Nijhoff Publishers, Dordrecht, 1989.

Fleck, Isabel, "Brasil quer reatar com órgão que criticou Belo Monte", Folha de São Paulo, 07/08/12, em http://www1.folha.uol.com.br/ $\mathrm{fsp} /$ mundo/112572-brasil-quer-reatar-com-orgao-que-criticoubelo-monte.shtml, acesso em 25/01/15.

Franck, Thomas, Fairness in international law and institutions, $2^{\circ}$ ed., Oxford University Press, New York, 1995.

Hobbes, Thomas, Leviathan, Dover Publications, London, 2006.

ILA Study Group, The Burgh House principles on the independence of the international judiciary, Burgh House, London, 2004, em http:/ / www.pict-pcti.org/ activities/Burgh\%20House\%20French.pdf, acesso em 11/02/15.

Kant, Immanuel, To perpetual peace, Hacket, Indianapolis, 2003.

Keylor, William R., The twentieth century world: an international history, $2^{\circ}$ ed.,Oxford University Press, New York, 2004.

Lissitzyn, Oliver J., The International Court of Justice - Its role in the maintenance of international peace and security, The Lawbook Exchange, New Jersey, 2008.

Malenovsky, Jiri, "Les opinions séparées et leurs répercussions sur l'indépendance du juge international", ACDI, 2010, 3, p. 27, em http:// revistas.urosario.edu.co/index.php/acdi/article/view/1424/1304, acesso em 11/02/15. 
Maupas, Stéphanie, "Génocide : la justice internationale renvoie Serbes et Croates dos à dos", Le Monde, 03/02/15, em http://abonnes. lemonde.fr/europe/article/2015/02/03/genocide-la-justice-internationale-renvoie-serbes-et-croates-dos-a-dos_4569187_3214. html, acesso em 05/02/15.

Mazzuoli, Valério O., Curso de direito internacional público, $2^{\circ}$ ed., Revista dos Tribunais, São Paulo, 2007.

Mcwhinney, Edward, The International Court of Justice and the Western tradition of international law, Martinus Nijhoff Publishers, Dordrecht, 1987.

Menezes, Wagner, Tribunais internacionais. Jurisdição e competência, Saraiva, São Paulo, 2013.

Muller, A. Sam \& Thuranszky, J. M., The International Court of Justice: it's role after fifty years, Martinus Nijhoff Publishers, Haia, 1997.

Patriota, Guilherme de A., "Dois pesos, duas medidas", Folha de São Paulo, 07/08/12, em http:/ /www1.folha.uol.com.br/fsp/opiniao/59211dois-pesos-duas-medidas.shtml, acesso em 25/01/15.

Pomerance, Michla, The United States and the World Court as the Supreme Court of the nations: dreams, illusions and disillusion, Martinus Nijhoff Publishers, Dordrecht, 1997.

Posner, Eric A., "Is the International Court of Justice biased?", Journal of Legal Studies, 34, (599), 2005.

Posner, Eric A., "The decline of the International Court of Justice", in Voight, Stefan (Org.), International conflict resolution, New York, 2006.

Quoc Dinh, Nguyen; Daillier, Patrick; Forteau, Mathias \& Pellet, Alain, Droit international public, $8^{\circ}$ ed., LGDJ, Paris, 2010.

Rezek, J. Francisco, Direito internacional público, $9^{\circ}$ ed., Saraiva, São Paulo, 2002. Rosenne, Shabtai, An international law miscellany, Martinus Nijhoff Publishers, Dordrecht, 1993.

Rosenne, Shabtai, The Court and the United Nations, Koninklijke Brill NV, Leiden, 2006.

Rosenne, Shabtai, The World Court: what it is and how it works, $6^{\circ}$ ed., Brill Academic Publishers, Leiden, 2003.

Singh, Nagendra, The role and record of the International Court of Justice,Martinus Nijhoff Publishers, Dordrecht, 1989.

United Nations, The International Court of Justice - Questions and answers about the principal judicial organ of the United Nations, 10 ed., United Nations, New York, 2000.

Varella, Marcelo D., Direito internacional público, Saraiva, São Paulo, 2009. 